\title{
Single-Crystalline Ultrathin Nickel Nanosheets Array from In Situ Topotactic Reduction for Active and Stable Electrocatalysis
}

\author{
Yun Kuang ${ }^{+}$, Guang Feng ${ }^{+}$, Pengsong Li, Yongmin Bi, Yaping Li, and Xiaoming Sun*
}

\begin{abstract}
Simultaneously synthesizing and structuring atomically thick or ultrathin $2 D$ non-precious metal nanocrystal may offer a new class of materials to replace the state-of-art noblemetal electrocatalysts; however, the synthetic strategy is the bottleneck which should be urgently solved. Here we report the synthesis of an ultrathin nickel nanosheet array (Ni-NSA) through in situ topotactic reduction from $\mathrm{Ni}(\mathrm{OH})_{2}$ array precursors. The Ni nanosheets showed a single-crystalline lamellar structure with only ten atomic layers in thickness and an exposed (111) facet. Combined with a superaerophobic (low bubble adhesive) arrayed structure the Ni-NSAs exhibited a dramatic enhancement on both activity and stability towards the hydrazine-oxidation reaction $(\mathrm{HzOR})$ relative to platinum. Furthermore, the partial oxidization of Ni-NSAs in ambient atmosphere resulted in effective water-splitting electrocatalysts for the hydrogen-evolution reaction (HER).
\end{abstract}

$T_{\text {wo-dimensional (2D) crystals with atomic thickness have }}$ attracted extensive attention because of the dramatically increased surface/volume ratio and unique electronic structures. ${ }^{[1-9]}$ Thus, they have been considered as promising materials in electronics, ${ }^{[10-14]}$ optics, ${ }^{[15,16]}$ magnetics, ${ }^{[17,18]}$ and catalysis. $^{[19,20]}$

Active and stable metal-based 2D crystals have shown a great potential as efficient electrocatalysts. ${ }^{[6,21]}$ However, the bottom-up synthesis of ultrathin nanosheets mainly relies on whether the material itself has a lamellar structure, ${ }^{[3,21-24]}$ while metal atoms have a strong preference for close-packed crystalline structures, ${ }^{[25-29]}$ and rich dangling bonds would make the nanosheets extremely active and unstable. ${ }^{[30]}$ Therefore, ultrathin metallic 2D structures with a plethora of unsaturated atoms are difficult to stabilize and only quite a few ligand-capped noble-metal ultrathin structures can be synthesized. ${ }^{[6,30-32]}$ Up to now, non-ligand-caped 2D transition-metal nanostructures remained big synthetic challenges.

$\left[{ }^{[*}\right]$ Dr. Y. Kuang, ${ }^{[+]}$G. Feng, ${ }^{[+]}$P. Li, Y. Bi, Dr. Y. Li, Prof. X. Sun State Key Laboratory of Chemical Resource Engineering Beijing University of Chemical Technology

Beijing 100029 (P.R. China)

E-mail: sunxm@mail.buct.edu.cn

$\left.{ }^{+}\right]$These authors contributed equally to this work.

16. Supporting information and $\operatorname{ORCID(s)}$ from the author(s) for this

(iD article are available on the WWWW under http://dx.doi.org/10.1002/ anie. 201509616

Of (c) 2015 The Authors. Published by Wiley-VCH Verlag GmbH \& Co. $\mathrm{KGaA}$. This is an open access article under the terms of the Creative Commons Attribution Non-Commercial License, which permits use, distribution and reproduction in any medium, provided the original work is properly cited and is not used for commercial purposes.
On the other hand, liquid exfoliation of organic-inorganic precursors has been demonstrated an effective way for preparation of atomically thick $2 \mathrm{D}$ crystals with a non-layered structure as well as the quasi-layered structure, but this strategy is so far not applicable to $2 \mathrm{D}$ metallic nanostructures. ${ }^{[33,34]}$ Therefore, developing a new synthetic route for ultrathin 2D metallic nanostructures, especially non-noble metals, will greatly expand the 2D material family and promote their applications.

Here, we synthesized ultrathin nickel nanosheets by gently reducing a $\mathrm{Ni}(\mathrm{OH})_{2}$ nanosheet array on a metal substrate under mild reducing conditions. The slow conversion kinetics kept the ultrathin nanosheet morphology and atomic thickness. The Ni nanosheets showed a single-crystalline lamellar structure with a thickness of only ten atomic layers and an exposed (111) facet. With plenty of active surface atoms, a single-crystalline structure, a superaerophobic (low bubble adhesive) surface, and a tunable surface state, the Ni-NSA showed a dramatic enhancement of both activity and stability on the hydrazine-oxidation reaction ( $\mathrm{HzOR})$ and hydrogen-evolution reaction (HER) relative to platinum, demonstrating the promising electrocatalytic applications of such ultrathin non-precious metal nanosheets.

Scheme 1 shows the in situ topotactic reduction procedure of the ultrathin Ni-NSA. Firstly, $\mathrm{Ni}(\mathrm{OH})_{2}$ nanowall arrays were grown on a nickel foam following our previous report, ${ }^{[35]}$ as evidenced by the X-ray diffraction (XRD) pattern (Figure $1 \mathrm{~A}$ ) of typical $\mathrm{Ni}(\mathrm{OH})_{2}$ peaks after growth of $\mathrm{Ni}(\mathrm{OH})_{2}$ arrays on a $\mathrm{Ni}$ substrate. Then the as-formed $\mathrm{Ni}(\mathrm{OH})_{2}$ nanowalls were solvothermally reduced in ethylene glycol

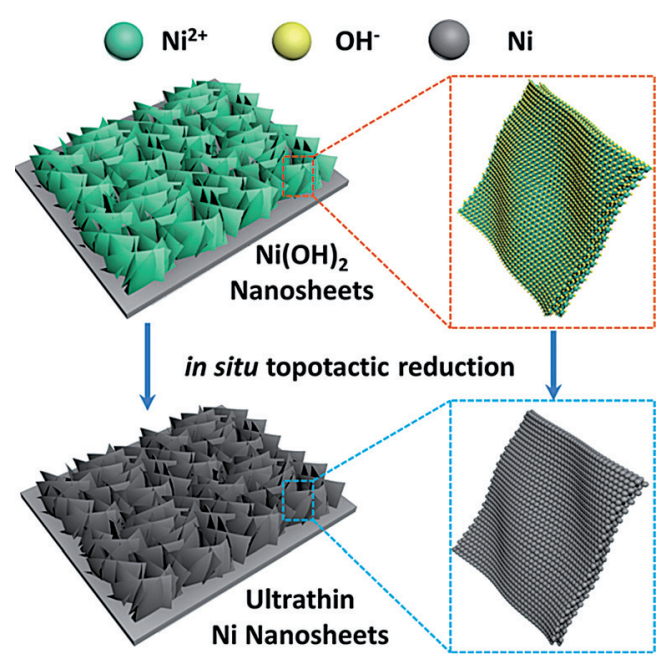

Scheme 1. In situ topotactic reduction method for fabrication of the atomically layered $\mathrm{Ni}$ nanosheet array. 

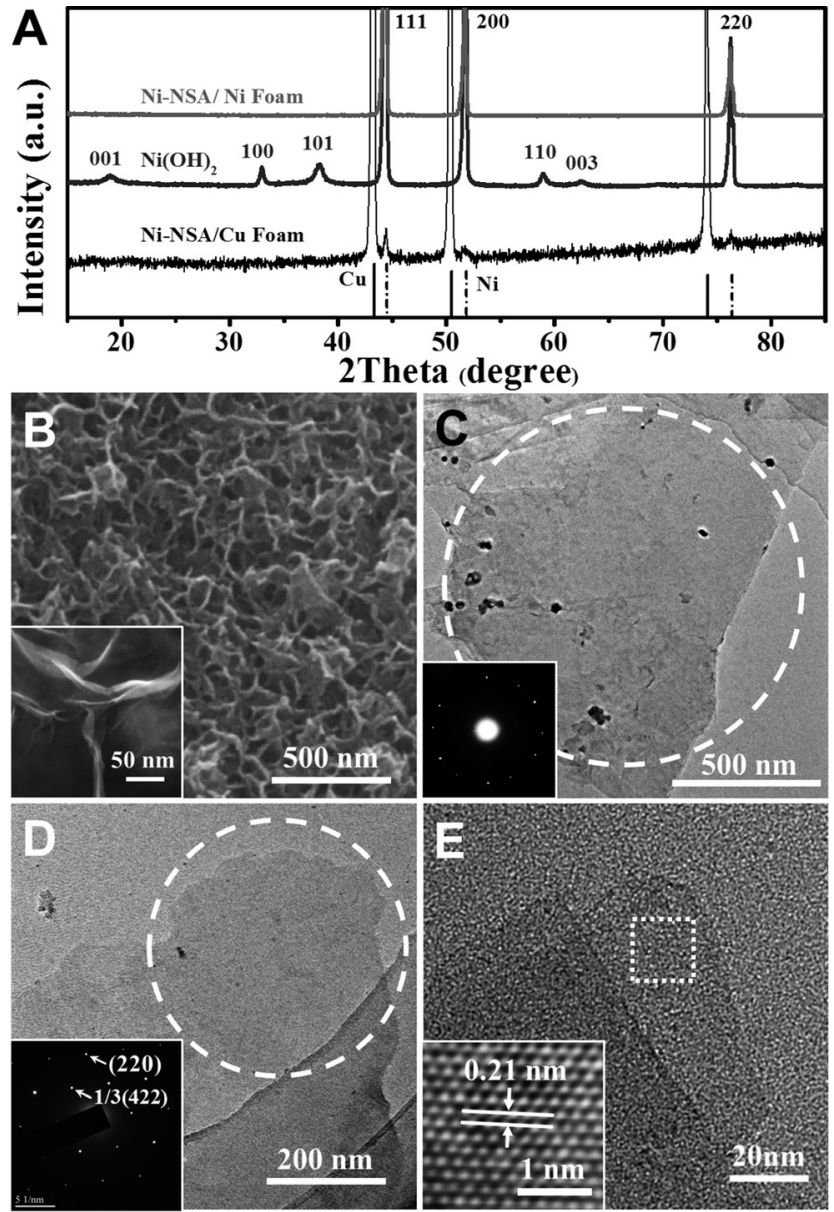

Figure 1. A) XRD pattern of the $\mathrm{Ni}(\mathrm{OH})_{2}$ nanosheet array and Ni-NSA grown on an $\mathrm{Ni}$ foam substrate and a $\mathrm{Cu}$ foam substrate. The two lines at the base show standard XRD patterns of $\mathrm{Cu}$ and Ni metals. B) SEM and HRSEM (inset) images of as synthesized Ni-NSA. C,D) TEM and corresponding electron diffraction pattern of C) two overlapped $\mathrm{Ni}$ nanosheets and $\mathrm{D}$ ) a single layered region, demonstrating a single-crystalline structure. E) HRTEM image (inset shows crystal lattices) of $\mathrm{Ni}$ nanosheets.

assisted by $\mathrm{NaOH} \cdot{ }^{[36]}$ The exclusive face-centered cubic (fcc) phase $\mathrm{Ni}$ patterns of the sample after reduction suggested complete reduction from $\mathrm{Ni}(\mathrm{OH})_{2}$ to $\mathrm{Ni}$. In order to confirm that the reduced product was $\mathrm{Ni}$ and to exclude the influence of the Ni substrate, the same Ni-NSA sample was synthesized on a $\mathrm{Cu}$ substrate (black line in Figure $1 \mathrm{~A}$, see Figure $\mathrm{S} 1$ in the Supporting Information for a SEM image). Appearance of (111), (200), and (220) peaks of the Ni crystal confirmed complete reduction of the sample.

The morphology of the obtained ultrathin Ni-NSA was characterized by scanning electron microscopy (SEM) and transmission electron microscopy (TEM). Figure 1B shows a $3 \mathrm{D}$ open porous array structure of the reduced Ni nanosheets, and each nanosheet was vertically grown on the substrate with hundreds of nanometers in size. However, the thickness of the nanosheets was as thin as only several nanometers, which could be read from the HRSEM image. The relatively low contrast of the nanosheets in the TEM images (Figure 1C-E) implied ultrathin structures. The electron diffraction pattern of the two overlapping Ni nanosheets (Figure $1 \mathrm{C}$ inset, S2) revealed the single crystallinity of the as-obtained $\mathrm{Ni}$ nanosheets while the electron diffraction pattern (Figure 1D) and enlarged HRTEM image (Figure 1E inset) of a single-layered region show face-centered cubic (fcc) nickel with 1/3(422) and (220) lattices on the sheet plane, which is in good agreement with previous observations on metallic fcc nanoplatelets, ${ }^{[6]}$ suggesting the nickel nanosheets have (111) basal planes.
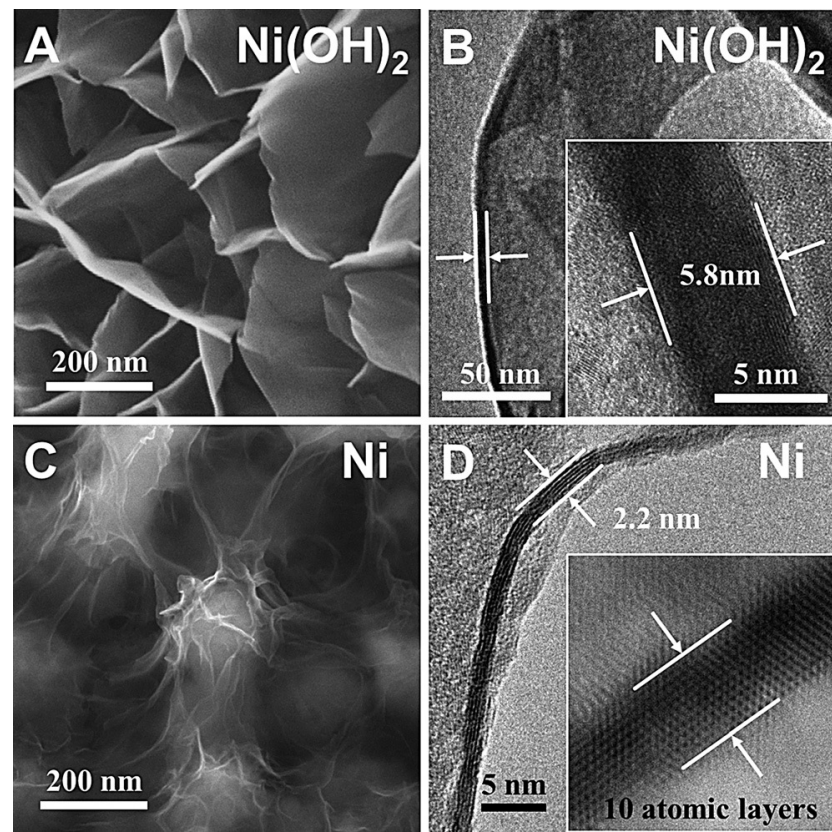

Figure 2. $\mathrm{A}, \mathrm{C}) \mathrm{SEM}$ images of an as-synthesized $\mathrm{Ni}(\mathrm{OH})_{2}$ nanowall array and $\mathrm{Ni}$-NSA. B,D) HRTEM image of a scrolled $\mathrm{Ni}(\mathrm{OH})_{2}$ nanowall and a vertically laid $\mathrm{Ni}$ nanosheet. The inset shows the thickness of the $\mathrm{Ni}(\mathrm{OH})_{2}$ nanowall and $\mathrm{Ni}$ nanosheet.

Figure 2 reveals the morphology inherence between NiNSA and the $\mathrm{Ni}(\mathrm{OH})_{2}$ nanowall array (i.e. in situ conversion). SEM images (Figure 2 A and C) show that Ni-NSA inherit the high porosity of the $\mathrm{Ni}(\mathrm{OH})_{2}$ array after in situ conversion, but the Ni nanosheets were much thinner than the $\mathrm{Ni}(\mathrm{OH})_{2}$ nanowalls. The HRTEM image of a scrolled $\mathrm{Ni}(\mathrm{OH})_{2}$ nanowall (Figure 2B) shows that the thickness of the nanowall was in the range of 5-6 $\mathrm{nm}$ (i.e. $10-12 \mathrm{Ni}$ layers), while the $\mathrm{Ni}$ nanosheet (Figure 2D) was as thin as only $2.2 \mathrm{~nm}$ (i.e. 10 atomic layers) typically, demonstrating an ultrathin lamellar structure. The coincidence of the $\mathrm{Ni}$ atomic layer numbers suggests an in situ topotactic reduction pathway from the $\mathrm{Ni}(\mathrm{OH})_{2}$ nanowall array to Ni-NSA. Characterization and analysis on the topotactic conversion intermediates $(0,3,6,9$, and $12 \mathrm{~h}$ ) through HRTEM, electron diffraction patterns (Figure S3), and XRD patterns (Figure S4) revealed that the in situ reduction from $\mathrm{Ni}(\mathrm{OH})_{2}$ to $\mathrm{Ni}$ experienced a phase transformation from hexagonal phased $\mathrm{Ni}(\mathrm{OH})_{2}$ to cubic phased $\mathrm{NiO}$ through dehydration, followed by a reduction from cubic $\mathrm{NiO}$ to fcc $\mathrm{Ni}$.

A lamellar structure is not thermodynamically favorable for fcc metallic structures; therefore, the in situ reduction 
kinetics must be well-controlled to avoid self-nucleation. Lower temperatures $\left(<140^{\circ} \mathrm{C}\right)$ would resulted in incomplete reduction of $\mathrm{Ni}(\mathrm{OH})_{2}$ (Figure $\mathrm{S} 5 \mathrm{~B}-\mathrm{C}$ ) while higher temperatures $\left(>180^{\circ} \mathrm{C}\right)$ would lead to a too fast reduction and cause new nucleation, resulting in nanospheres (Figure S5E-F).

The single-crystalline ultrathin $2 \mathrm{D}$ structure endowed $\mathrm{Ni}$ NSA with an extremely high ratio of surface atoms and structure stability (low atom mobility), which was demonstrated by ultrahigh electrocatalytic performance (Figure 3 ).

A
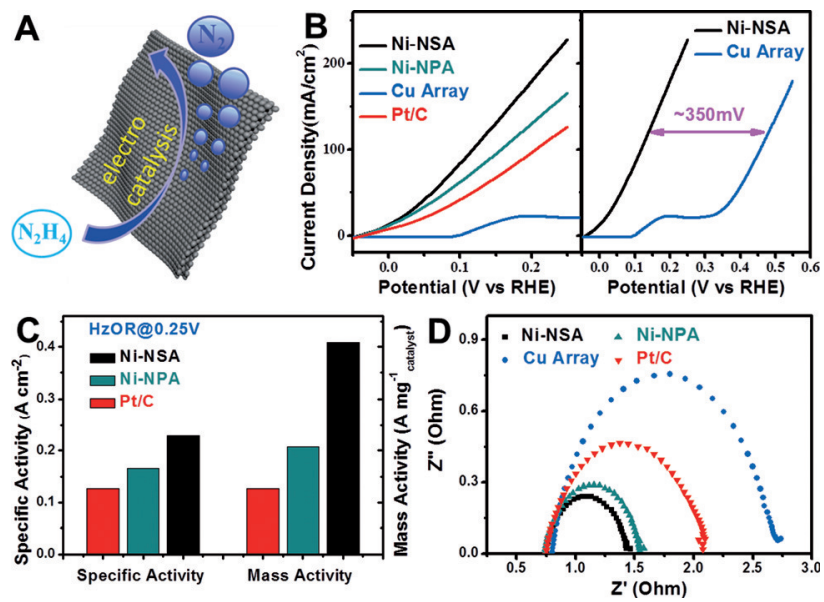

Figure 3. A) Schematic of the Ni-NSA catalytic hydrazine oxidation. B) $\mathrm{HzOR}$ performance of $\mathrm{Ni}-\mathrm{NSA}, 3 \mathrm{D}$ porous $\mathrm{Ni}$ nanoparticle assembly (Ni-NPA), Cu nanosheet array, and commercial Pt/C (loaded on a $\mathrm{Ni}$ foam). C) Comparison of the specific activity and mass activity of $\mathrm{Ni}$ NSA, Ni-NPAs, and 20 wt \% Pt/C. An $81 \%$ enhancement was observed for Ni-NSA. The specific activity and mass activity were currents normalized to geometric areas of the nickel foam substrates and the mass loading of the samples, respectively. D) Nyquist plots of the four electrodes, indicating that Ni-NSA possessed a much smaller chargetransfer resistance. Note: the loading amount of $\mathrm{Pt} / \mathrm{C}$ was twice that of Ni-NSA because of the poor adhesion to the substrate. The mass loadings of Ni-NSA and Ni-NPA were $0.59 \mathrm{mg} \mathrm{cm}^{-2}$ and $0.81 \mathrm{mg} \mathrm{cm}^{-2}$, respectively.

As an example, Figure $3 \mathrm{~B}$ compares the electrocatalytic hydrazine oxidation ( $\mathrm{HzOR}$ ) performance of Ni-NSA, 3D porous Ni nanoparticle assembly (Ni-NPA), commercial Pt/C (loaded on $\mathrm{Ni}$ foam), and reported $\mathrm{Cu}$ nanosheet array ${ }^{[37]}$ electrodes. The onset potential $\left(E_{\text {on }}\right)$ of Ni-NSA was about $300 \mathrm{mV}$ lower than that reported for the $\mathrm{Cu}$ nanosheet array and even lower than that of $\mathrm{Pt} / \mathrm{C}$, demonstrating a much higher intrisic activity. For quantitative comparison, the kinetic currents were normalized to the active area of the substrates and the mass loading of the catalysts (Figure 3C), respectively. At the same potential of $0.25 \mathrm{~V}$, the Ni-NSA electrode afforded a considerable specific activity $\left(227.6 \mathrm{~mA} \mathrm{~cm}^{-2}\right)$ and mass activity $\left(406.4 \mathrm{~mA} \mathrm{mg}^{-1}\right.$ catalyst $)$, which were 1.81 times and 3.25 times higher than that of the $\mathrm{Pt} / \mathrm{C}$ catalyst. Besides the high intrinsic activity, the ultrathin Ni-NSAs also possess rough surfaces, which could cut the liquid-solid-gas three-phase contact line into tiny pieces during the electrocatalytic gas-evolution process, thus exhibiting superaerophobic surfaces, like the $\mathrm{MoS}_{2}$ nanosheet arrays previously reported by us. ${ }^{[38]}$ Such superaerophobic surfaces could facilitate mass transfer on catalyst surfaces and thus facilitate a current increase during electrocatalysis. As shown in adhesion force tests in Figure S6, the Ni-NSAs showed almost no adhesion force to the gas bubbles; in contrast to the severe adhesion force of $\mathrm{Pt} / \mathrm{C}$. Thus, the superaerophobic Ni-NSA showed a small releasing size and fast removal of as-formed $\mathrm{N}_{2}$ gas bubbles (Movie S1) while severe adhesion of gas bubbles on the $\mathrm{Pt} / \mathrm{C}-\mathrm{Ni}$ foam led to serious blockage of the electrocatalytic active sites, resulting in a much bigger releasing size of the bubbles and a low electrocatalytic performance (Movie S2). No cleaning/activation step was involved for Ni-NSA before the HzOR test, implying clean surfaces of the products.

In order to further illustrate the advances of atomically thick 2D structure, we prepared a 3D porous Ni nanoparticle assembly sample for comparison (Ni-NPA, see the SEM image in Figure S7 for the morphology) following a similar procedure but under harsher reduction conditions. The NiNPA was deliberately made 3D open porous and superaerophobic, thus both Ni-NSA and Ni-NPA were composed of the same materials and showed similar surface properties. A comparison of their electrocatalytic performances reflected the intrinsic property difference. As shown in Figure 3, NiNSA exhibited a 1.97 times higher activity (Figure 3C) and a lower charge-transfer resistance (ca. $69 \Omega$ ) in Nyquist plots (Figure 3D), revealing a much higher intrinsic electrocatalytic performance, largely because of its ultrathin 2D structure, ultrahigh surface area, and a plethora of unsaturated atoms (i.e. surface atoms, step/corner atoms), which could act as highly active electrocatalytic sites. ${ }^{[39]}$ Combined with a single-crystalline structure and superaerophobic surfaces, the Ni-NSA showed $91.8 \%$ (Figure S8) of its original current density and no structural damage (Figure S9) after a $10000 \mathrm{~s}$ harsh stability test in highly concentrated $\mathrm{N}_{2} \mathrm{H}_{4}$ solution, suggesting long-term stability.

The Ni-NSAs also showed a high activity towards the hydrogen-evolution reaction (HER) after partial oxidation by exposure in ambient atmosphere for a while (Figure 4A,C). The HRTEM image (Figure 4B) and the corresponding fast Fourier transformation (FFT) pattern of a partially oxidized Ni nanosheet show two crystalline lattices that are indexed as $\mathrm{Ni}$ 1/3(422) and $\mathrm{NiO} 1 / 3(422)$ facets, revealing the existence of $\mathrm{NiO}$ on $\mathrm{Ni}$ surfaces. However, the $\mathrm{NiO}$ signal in the FFT pattern was relatively weak, demonstrating that only a small part of the surfaces was oxidized. X-ray photoelectron spectroscopy (XPS) spectroscopy confirmed the co-existence of $\mathrm{Ni}^{\mathrm{II}}$ and $\mathrm{Ni}^{0}$ (Figure $\mathrm{S} 10$ ).

Surprisingly, it is found that partial oxidization of $\mathrm{Ni}$ NSAs under low-pressure air conditions (vacuum oven, ca. $1 \times$ $10^{3} \mathrm{Par}$ ) for $6 \mathrm{~h}$ showed the best HER performance (Figure $4 \mathrm{C}$ ). Under this condition, the $\mathrm{Ni} / \mathrm{NiO}-\mathrm{NSAs}$ showed an onset potential of $-34 \mathrm{mV}$ in $0.1 \mathrm{M} \mathrm{KOH}$ (Figure $4 \mathrm{D}$ inset) and a Tafel slope of $114 \mathrm{mV}$ per decade (Figure S11), which is better than that of the Ni/NiO-NPA counterpart (135 mV per decade) because of its structural advantage. Besides, the current increase of $\mathrm{Ni} / \mathrm{NiO}-\mathrm{NSAs}$ was much faster than that of $\mathrm{Pt} / \mathrm{C}$ at a higher current (e.g. $100 \mathrm{mAcm}^{-2}$, Figure 4D) because of its high surface area and superaerophobic surface structure. The ultrathin $\mathrm{Ni} / \mathrm{NiO}-\mathrm{NSA}$ also exhibited a very 

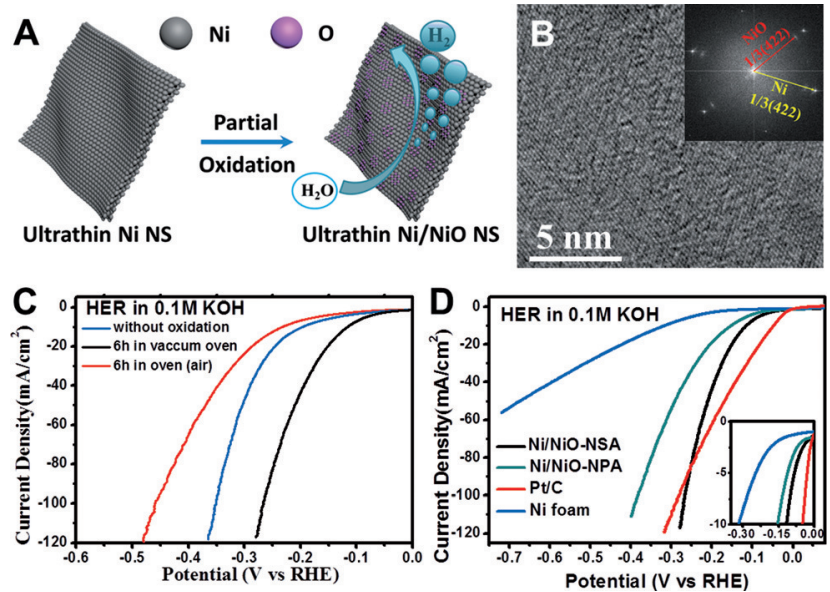

Figure 4. A) Schematic of partial oxidization on the Ni-NSA surface. B) HRTEM image and corresponding fast Fourier transformation (FFT) of a Ni nanosheet exposed in ambient atomsphere. C) HER performance of $\mathrm{Ni} / \mathrm{NiO}-\mathrm{NSAs}$ with different oxidation degree. D) HER polarization curves of $\mathrm{Ni} / \mathrm{NiO}-\mathrm{NSAs}, 3 \mathrm{D}$ porous $\mathrm{Ni} / \mathrm{NiO}$ nanoparticle assembly (Ni/NiO-NPA), pure $\mathrm{Ni}$ foam, and commercial Pt/C (loaded on the $\mathrm{Ni}$ foam). Note: the loading amount of $\mathrm{Pt} / \mathrm{C}$ was twice that of $\mathrm{Ni} / \mathrm{NiO}-\mathrm{NSA}$ because of the poor adhesion to the substrate.

high electrocatalytic stability. After $10 \mathrm{~h}$ stability testing, the $\mathrm{Ni} / \mathrm{NiO}-\mathrm{NSAs}$ still showed $94.9 \%$ (Figure S12) of its initial current density and no structural damage was found (Figure S9).

Such high HER performance was ascribed to a synergistic HER catalytic activity on the $\mathrm{Ni} / \mathrm{NiO}$ interface reported by Dai and co-workers. ${ }^{[40]}$ The $\mathrm{OH}^{-}$generated by $\mathrm{H}_{2} \mathrm{O}$ splitting preferred to attach to a $\mathrm{NiO}$ site at the interface because of a strong electrostatic affinity to the locally positively charged $\mathrm{Ni}^{2+}$ species and more unfilled d orbitals in $\mathrm{Ni}^{2+}$ than $\mathrm{Ni}$ metal, while a nearby $\mathrm{Ni}$ site would facilitate hydrogen adsorption and thus the Volmer process. Theoretical calculation revealed that desorption of $\mathrm{H}_{2}$ on $\mathrm{Ni} / \mathrm{NiO}$ (111) surfaces possesses a lower energy barrier $(3.228 \mathrm{eV})$ than on pure Ni (111) surfaces $(3.763 \mathrm{eV})$, supporting the above hypothesis.

In summary, ultrathin nickel nanosheet arrays (Ni-NSAs) were synthesized through a well-controlled in situ topotactic reduction/conversion kinetical process. Such method could achieve ultrathin nanostructures while maintain the original 2D morphology of the precursors. With plenty of active surface atoms and single-crystalline structure, the as-prepared ultrathin Ni-NSA was demonstrated as highly effective electrocatalysts for fuel-cell and water-splitting application with activity and stability higher than that of Pt. The in situ conversion method opened up a way for fabrication of $2 \mathrm{D}$ non-precious metal nanostructures and should be beneficial to the preparation of low-cost, highly efficient, and stable electrocatalysts and other related nanomaterials.

\section{Experimental Section}

$\mathrm{Ni}(\mathrm{OH})_{2}$ nanowall films were synthesized following our previous report. ${ }^{[35]}$ In a typical in situ topotactic reduction procedure, $\mathrm{NaOH}$ $(1 \mathrm{~g})$ and ethylene glycol $(\mathrm{EG} ; 36 \mathrm{~mL})$ were put into a $40 \mathrm{~mL}$ Teflon- lined stainless-steel autoclave, and stirred until the solid dissolved. Then $\mathrm{Ni}(\mathrm{OH})_{2}$ nanowall films were transferred to the autoclave and maintained at $160^{\circ} \mathrm{C}$ for $12 \mathrm{~h}$ to yield the final products. The thin nanosheets on the metal substrate were rinsed several times with distilled water and ethanol (all the solvents were bubbled with Ar to eliminate solved oxygen). The Ni-NSA should be stored in an environment without oxygen to avoid oxidation.

\section{Acknowledgements}

This work was supported by National Natural Science Foundation of China, the 973 Program (grant numbers 2011CBA00503 and 2011CB932403), and the Program for Changjiang Scholars and Innovative Research Team in the University.

Keywords: electrocatalysis - nanosheets - nickel · single crystals $\cdot$ ultrathin films

How to cite: Angew. Chem. Int. Ed. 2016, 55, 693-697 Angew. Chem. 2016, 128, 703-707

[1] A. K. Geim, K. S. Novoselov, Nat. Mater. 2007, 6, 183-191.

[2] M. Chhowalla, H. S. Shin, G. Eda, L.-J. Li, K. P. Loh, H. Zhang, Nat. Chem. 2013, 5, 263-275.

[3] K. S. Novoselov, D. Jiang, F. Schedin, T. J. Booth, V. V. Khotkevich, S. V. Morozov, A. K. Geim, Proc. Natl. Acad. Sci. USA 2005, 102, 10451-10453.

[4] B. Radisavljevic, A. Radenovic, J. Brivio, V. Giacometti, A. Kis, Nat. Nanotechnol. 2011, 6, 147-150.

[5] S. Z. Butler, S. M. Hollen, L. Cao, Y. Cui, J. A. Gupta, H. R. Gutiérrez, T. F. Heinz, S. S. Hong, J. Huang, A. F. Ismach, E. Johnston-Halperin, M. Kuno, V. V. Plashnitsa, R. D. Robinson, R. S. Ruoff, S. Salahuddin, J. Shan, L. Shi, M. G. Spencer, M. Terrones, W. Windl, J. E. Goldberger, ACS Nano 2013, 7, 2898 2926.

[6] X. Huang, S. Tang, X. Mu, Y. Dai, G. Chen, Z. Zhou, F. Ruan, Z. Yang, N. Zheng, Nat. Nanotechnol. 2011, 6, 28-32.

[7] Y. Sun, Z. Sun, S. Gao, H. Cheng, Q. Liu, J. Piao, T. Yao, C. Wu, S. Hu, S. Wei, Y. Xie, Nat. Commun. 2012, 3, 1057.

[8] Y. Sun, S. Gao, F. Lei, Y. Xie, Chem. Soc. Rev. 2015, 44, 623 - 636.

[9] M. Xu, T. Liang, M. Shi, H. Chen, Chem. Rev. 2013, 113, 37663798.

[10] K. S. Novoselov, A. K. Geim, S. V. Morozov, D. Jiang, Y. Zhang, S. V. Dubonos, I. V. Grigorieva, A. A. Firsov, Science 2004, 306, 666-669.

[11] M. Osada, T. Sasaki, Adv. Mater. 2012, 24, 210-228.

[12] Y. Zhang, Y.-W. Tan, H. L. Stormer, P. Kim, Nature 2005, 438, 201-204.

[13] A. Pronschinske, P. Pedevilla, C. J. Murphy, E. A. Lewis, F. R. Lucci, G. Brown, G. Pappas, A. Michaelides, E. C. H. Sykes, Nat. Mater. 2015, DOI: $10.1038 /$ nmat 4323.

[14] G. Le Lay, Nat. Nanotechnol. 2015, 10, 202-203.

[15] Q. H. Wang, K. Kalantar-Zadeh, A. Kis, J. N. Coleman, M. S. Strano, Nat. Nanotechnol. 2012, 7, 699-712.

[16] V. Perebeinos, Nat. Nanotechnol. 2015, 10, 485-486.

[17] X. Zhang, J. Zhang, J. Zhao, B. Pan, M. Kong, J. Chen, Y. Xie, J. Am. Chem. Soc. 2012, 134, 11908-11911.

[18] J. Yuan, J. Lou, Nat. Nanotechnol. 2015, 10, 389-390.

[19] M. Guan, C. Xiao, J. Zhang, S. Fan, R. An, Q. Cheng, J. Xie, M. Zhou, B. Ye, Y. Xie, J. Am. Chem. Soc. 2013, 135, 10411-10417.

[20] F. Song, X. Hu, Nat. Commun. 2014, 5, 4477.

[21] F. Saleem, Z. Zhang, B. Xu, X. Xu, P. He, X. Wang, J. Am. Chem. Soc. 2013, 135, 18304-18307. 
[22] J. N. Coleman, M. Lotya, A. O'Neill, S. D. Bergin, P. J. King, U. Khan, K. Young, A. Gaucher, S. De, R. J. Smith, I. V. Shvets, S. K. Arora, G. Stanton, H.-Y. Kim, K. Lee, G. T. Kim, G. S Duesberg, T. Hallam, J. J. Boland, J. J. Wang, J. F. Donegan, J. C. Grunlan, G. Moriarty, A. Shmeliov, R. J. Nicholls, J. M. Perkins, E. M. Grieveson, K. Theuwissen, D. W. McComb, P. D. Nellist, V. Nicolosi, Science 2011, 331, 568-571.

[23] X. Huang, Z. Zeng, H. Zhang, Chem. Soc. Rev. 2013, 42, $1934-$ 1946.

[24] K.-K. Liu, W. Zhang, Y.-H. Lee, Y.-C. Lin, M.-T. Chang, C.-Y. Su, C.-S. Chang, H. Li, Y. Shi, H. Zhang, C.-S. Lai, L.-J. Li, Nano Lett. 2012, 12, 1538-1544.

[25] Y. Xia, Y. Xiong, B. Lim, S. E. Skrabalak, Angew. Chem. Int. Ed. 2009, 48, 60-103; Angew. Chem. 2009, 121, 62-108.

[26] A. R. Tao, S. Habas, P. Yang, Small 2008, 4, 310-325.

[27] J. Gu, Y.-W. Zhang, F. Tao, Chem. Soc. Rev. 2012, 41, 8050-8065.

[28] D. Wang, Y. Li, Adv. Mater. 2011, 23, 1044-1060.

[29] M. Chen, B. Wu, J. Yang, N. Zheng, Adv. Mater. 2012, 24, 862 879.

[30] H. Duan, N. Yan, R. Yu, C.-R. Chang, G. Zhou, H.-S. Hu, H. Rong, Z. Niu, J. Mao, H. Asakura, T. Tanaka, P. J. Dyson, J. Li, Y. Li, Nat. Commun. 2014, 5, 3093.

[31] R. Jin, Y. Cao, C. A. Mirkin, K. L. Kelly, G. C. Schatz, J. G. Zheng, Science 2001, 294, 1901-1903.
[32] J. E. Millstone, S. J. Hurst, G. S. Métraux, J. I. Cutler, C. A. Mirkin, Small 2009, 5, 646-664.

[33] X. Zhang, Y. Xie, Chem. Soc. Rev. 2013, 42, 8187-8199.

[34] Y. Sun, H. Cheng, S. Gao, Q. Liu, Z. Sun, C. Xiao, C. Wu, S. Wei, Y. Xie, J. Am. Chem. Soc. 2012, 134, 20294-20297.

[35] Z. Lu, Z. Chang, W. Zhu, X. Sun, Chem. Commun. 2011, 47, $9651-9653$.

[36] M. Cheng, M. Wen, S. Zhou, Q. Wu, B. Sun, Inorg. Chem. 2012 , $51,1495-1500$.

[37] Z. Lu, M. Sun, T. Xu, Y. Li, W. Xu, Z. Chang, Y. Ding, X. Sun, L. Jiang, Adv. Mater. 2015, 27, 2361-2366.

[38] Z. Lu, W. Zhu, X. Yu, H. Zhang, Y. Li, X. Sun, X. Wang, H. Wang, J. Wang, J. Luo, X. Lei, L. Jiang, Adv. Mater. 2014, 26 , $2683-2687$.

[39] T. Fujita, P. Guan, K. McKenna, X. Lang, A. Hirata, L. Zhang, T. Tokunaga, S. Arai, Y. Yamamoto, N. Tanaka, Y. Ishikawa, N. Asao, Y. Yamamoto, J. Erlebacher, M. Chen, Nat. Mater. 2012, $11,775-780$.

[40] M. Gong, W. Zhou, M.-C. Tsai, J. Zhou, M. Guan, M.-C. Lin, B. Zhang, Y. Hu, D.-Y. Wang, J. Yang, S. J. Pennycook, B.-J. Hwang, H. Dai, Nat. Commun. 2014, 5, 4695.

Received: October 14, 2015

Published online: November 19, 2015 